\title{
Present Leprosy Situation in India and the Decade Long Experience of This Correspondent
}

\author{
Bhairab Chandra Mandal* \\ Regional Leprosy Training \& Research Institute, Gouripur, Bankura, WB, India \\ Leprosy Research Center, National Institute Of Infectious Diseases, Tokyo, Japan
}

[Received: 12 Oct 2000 ]

Key words: Silent neuritis, SLPB, MLEC, Residual lesions, ENL.

Leprosy, which was known to ancient India as "Kustha Roga" is thought to be its origin from India also. It is, still, a major public health problem in India affecting many people every year. India is, now, having maximum numbers of leprosy cases worldwide and accounts for $67 \%$ of total prevalence and $73 \%$ of total new case detection. Huge numbers of new cases have been detected in recent years (Last year new cases were 782501) because of adoption of new strategy, Modified Leprosy Elimination compaign (MLEC), and effective health education campaign. Presently, $70 \%$ of the total new caseloads of India are from five most heavily infected states. There is significant improvement in the overall situation as is evident from steady decline of prevalence rate from 38.6 cases per 10,000 population in 1985 to 5.0 per 10,000 in 1999 .

Leprosy is, still, a major public health problem in India affecting many people every year from all walks of life irrespective of age, sex, religion and social status, though more common among the poor and majority of patients attending our out patient department (OPD) are from the poorer section. India is having the maximum numbers of leprosy cases worldwide and presently accounts for $67 \%$ and $73 \%$ of total prevalence and newly detected cases respectively ${ }^{1)}$.

History. It is believed that leprosy has its origin from ancient India and mention of the disease as "Kustha roga" has been found in "Sushrata Sanhita", a book on Ayurved, written about 600 years B. C. Sushrata - the great indian ayurvedic physician treated his patients at that time with "Chalmoogra oil". It is, also, thought that leprosy reaches Europe from India with the return of the greek soldiers of the Alexjander - the great in 327 B.C ${ }^{2), 3)}$.

Short geography \& People. India is big and the second most populous country, after China in the world. Population recently has crossed one billion. It is a multi-religious, multi-linguistics, multi- cultural country having many deep forests, rivers, mountains, hills and many villages scattered all over with a large difficult terrain not easily accessible. Many

*Corresponding author:

Regional Leprosy Training \& Research Institute (RLTRI), Gouripur, P.O: GOURIPUR,

District: BANKURA, WB, INDIA, PIN 722132

Tel:(91) 3242-77318; (91) 3242-52282 
people are poor and a number of people are illiterate. India is the homeland of many tribes. Many taboos are, still, practiced at the village level. Majority of the Indian people live in the villages and cultivation is the main source of income. At present, there are 26 numbers of states and 6 numbers of union territories (U T) in India.

Distribution of leprosy cases. Though leprosy is a common health problem throughout India but the distribution of cases is not uniform. Some states and U T's have been found with high endemicity of leprosy, some are having moderate and some are low. Interestingly, those states and $\mathrm{U} T$ situated bordering the Bay of Bengal were having the maximum numbers of leprosy patients since long back years. These bordering states prevalence rates $(\mathrm{P} / \mathrm{R})$ of leprosy per 1,000 population in $1985-86$ were - Tamilnadu (TN) - 15.14, Orrisa - 12.14, Andhra Pradesh (AP) - 11.58 and West Bengal (WB)- 7.88 in order of descending number of patients and Pondicherry - a UT was 31.67 4). Reasons for that specific type of case distribution is not yet clear. In general, the disease is more prevalent in the southern and eastern regions than in the northern regions of the country ${ }^{3)}$. States e.g. Bihar ( P/R at present 15/ 10000), Madhya Pradesh (M P), Maharastra, Karnataka, Kerala bordering the previously mentioned states were considered moderate in endemicity. North, North Western and some north eastern states are low endemic. Now, five states e.g. Bihar, Uttar Pradesh (UP), WB, Orrisa, and MP are having maximum leprosy problem, case load $70 \%$ of the total in India. Also, some states (10 states) in India have already been achieved the goal of WHO of less than 1 in 10,000 ${ }^{1}$.

Leprosy control programme in India. Official fight against leprosy was started in India from the middle of 1954 as National Leprosy Control Programme. In 1983 it was converted into National Leprosy Eradication Programme ${ }^{3)}$. Since the establishment of control programme some special and constructive steps had been taken up like setting up of special hospitals in different areas of the country, especially, in highly endemic states for leprosy vic- tims to provide care and treatment on OPD basis as well as in the indoor wards. Research and training institutes, also, came up for further scientific and advance studies on leprosy. Central Leprosy Training \& Research Institute (CLTRI), Chingelput and JALMA, Agra were the fruit of special endeavors. JALMA, Agra was taken up by Indian Council of Medical Research (ICMR) in 1972. These two institutes are playing the crucial roles, now, in training and advance studies. National Leprosy Eradication Programme set up in 1983 was renamed subsequently, as National Leprosy Elimination Programme, (NLEP), which is now under operation throughout India.

Situation before the introduction of multi drug therapy (MDT). Before the introduction of MDT there was no active system, as it is in vogue now, of detecting new cases though there were plenty of cases at that time. Naturally, detection of new cases, especially, in the early stages was minimal. There was no specific screening procedure under operation like now and health education (H E) on leprosy was little to create awareness among the people. So, stigmata's were much prevalent. In spite of that, with the assistance from social workers / volunteers, a significant numbers of cases detected yearly, many in the advanced stages, through the existing horizontal health system. The estimated number of cases in 1981was about 4 million, based on the average prevalence rate of 5.7 per 1000 population ${ }^{4)}$. About 2 to 3 lakhs new cases detected every year, and two lakhs cases either get discharged as cured or die ${ }^{3), 5}$. The compiled reports showed that $15-20$ percent of cases were MB and nearly $20 \%$ of them were children ${ }^{3,6)}$ during that period (1 lakh $=0.1$ million).

MDT program operation in India. Ministry of Health \& Family Welfare, Government of India - the policy maker and for all sorts of assistance on leprosy program in India, operates through different state governments, central govt. health depts. /institutes \& NGO's (a nos. of NGO are operating in Indian soil). MDT was recommended by WHO in 1981.In the next year i.e., in 1982 it was introduced 
first in two high endemic districts, Wardha (P/R- 9.7 $/ 1000)$ in Maharastra \& purulia (P/R 33/ 1000) in WB. Since then gradually, MDT program had been implemented throughout the country, in accordance with the P/R of districts and states and by the year 1991, so far I know, all the 493 districts of India have been brought under MDT network coverage. Since then MDT is available even in the remotest area of India. With MDT coverage active case detection and treatment by paramedics (Para-medical workersPMW \& Non-medical supervisor-NMS), under the direct guidance of Medical professionals are going on in full swing employing different means of survey procedures and health education (HE) campaign. Progress report (during 1998 - 99) of National Leprosy Elimination Programme (NLEP), Govt. of India, for case detection, treatment and discharge is produced below in part for want of space, as I am to write with in six pages. Table 1 shows the number of new cases detected and treated and number of Multi Bacillary (MB) cases and $\mathrm{P} / \mathrm{R}$ per 10,000 population of some important leprosy problem states/UT in India. It, also, shows over all leprosy situation in India, like total numbers of new cases detected and treated were 782,501 and 778,665 respectively. $\mathrm{P} / \mathrm{R}$ was 5.41 . Number of MB cases was 288,290 . It, also, shows Nagaland is the (first) state that has already achieved the goal of WHO. Five states e.g. Bihar, MP, Orrisa,
WB and UP were having the number of newly detected cases during the year altogether 554,549 out of the total 782,501 new detected cases and accounted for $70.86 \%$ of the total ${ }^{7}$. Number of child cases and its' percentage among the new patients were 114,616 and $14.65 \%$ respectively. $3.77 \%$ of new cases were found having disability Grade II. ${ }^{7)}$ (not in Table).

Figure 1 shows the year wise detection of new leprosy cases in India starting from 1985 to $1999^{11}$. Pillars and line in the figure indicate the $\mathrm{P} / \mathrm{R}$ of leprosy in 10,000 of population and numbers of newly detected cases respectively. $P / R$ is decreasing steadily from 38.6 in 1985 to 5.0 in 1999 except in 1998 when it was 5.9. Whereas numbers of newly detected cases were variable, especially, in recent years when detected numbers had been found to be increased significantly because of the adoption of new strategy e.g. Modified Leprosy Elimination Campaign (MLEC) to intensify case detection, in addition to, the existing case detection system. By this program (MLEC), with in a very short period of time (7-8 days), employing many staff and community volunteers, house to house search for individuals of a particular state, with a high endemicity of leprosy is carried out. Stress is, also, given to reach the remotest area and the difficult terrain of the concerned state / UT to book as many patient as possible. Little people can escape this examination procedure. Very good

Table 1. National leprosy elimination programme during 1998-1999 in some areas.

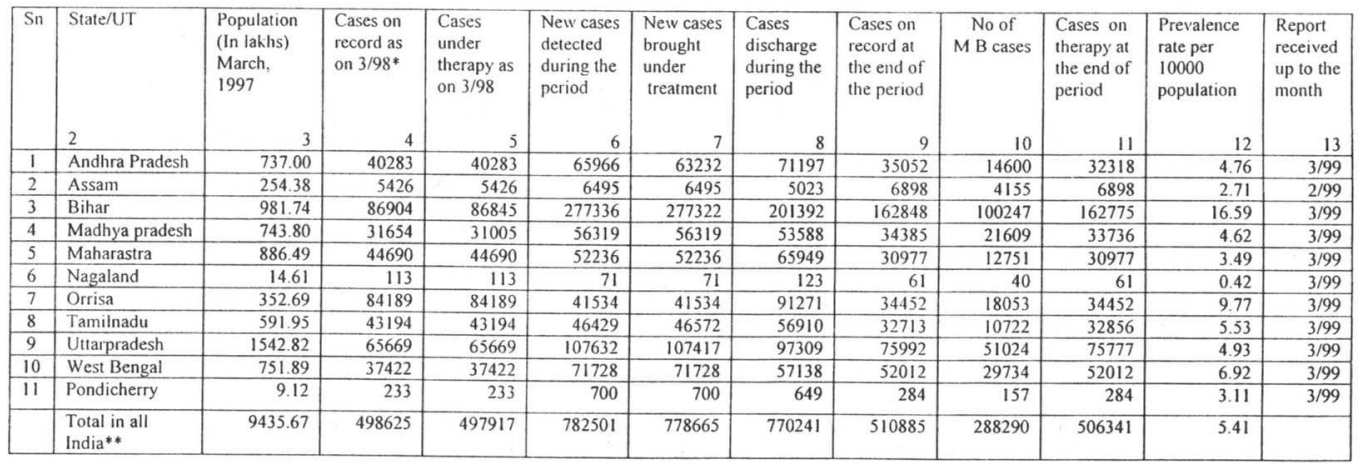

Tablel. National leprosy eradication programme during 1998-1999 in some areas.

*3/98 = March, 1998. **Total = All India Cases 
and encouraging results had been obtained by exercising this system. Recently, 62,844 new cases were detected in a week -long search in the state of Orissa in 1998 by this program. The same procedure was repeated in 1999 again in the same Orissa state $\left(30^{\text {th }}\right.$ January to $4^{\text {th }}$ February 1999) and detected 27,197 new cases by covering $85 \%$ of the population ${ }^{8}$. Though, these high numbers of cases are surprising but they do not reflect either the MDT failure or multi drug resistance (MDR leprosy). MDT has been found still working nicely in our OPD patients though I have seen a few cases of MB leprosy, remaining high positive in spite of MDT for more than 3 years with the signs of little decrease of $\mathrm{BI}$ and are the victims of repeated erythema nodosum leprosum (ENL).

\section{Discussion}

It can be said with much confidence that lep- rosy problem in India has improved significantly with the introduction of MDT and condition will continue to improve further with the passage of time. Though, the target of $P / R$ of 1 in 10,000 is not possible to achieve throughout India by 2000 (already 10 states out of 26 achieved the goal of $\mathrm{WHO}^{1)}$ ), it is presumed, with in next 3-5 years the goal can be successfully achieved, although leprosy will persist and continue at a low level in absence of effective vaccine and poor socio-economic condition. The remaining problem can be dealt effectively by the existing 'General Health Care' delivery system of the country even in the absence of vertical system in my opinion. Awareness on leprosy is growing fast and attitude of people about leprosy and the victims (Lepers) is also, rapidly changing as I have seen at the time of imparting health education in different village gatherings. Now, people have started to consider leprosy as a disease, caused by a tiny germ in stead

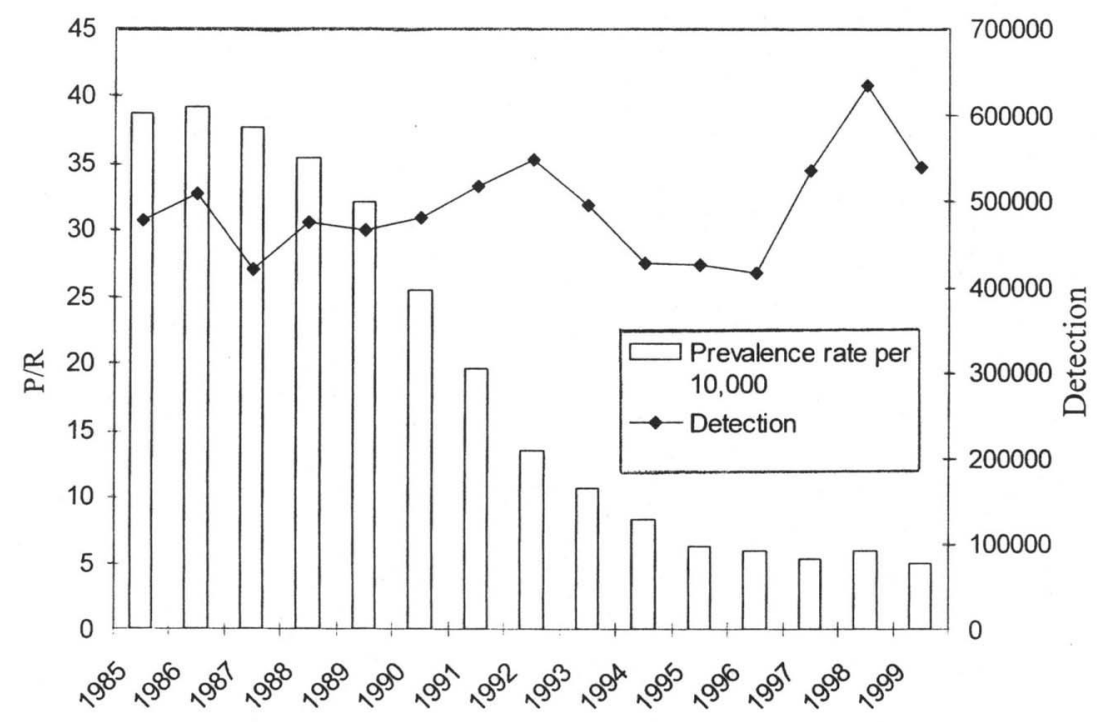

Figure 1. India Leprosy Trends-WHO Report. 
of a social problem arising out of committing $\sin /$ misdeeds by the victims or a curse from god. Health education (HE) is playing the key role for prevention, control and rehabilitation of leprosy cases by helping early case detection and it is going on in full swing involving many and different systems. MDT is making path way to cure patients and it minimizes disease transmission. Detection of huge numbers of new cases in recent years especially in children, about $15 \%$, needs specific mention. To protect this susceptible child group development of an effective vaccine is the need of the hour as BCG is non-protective (India now $100 \%$ covered by BCG vaccination). More over, an inexpensive, safe, reliable and easily performable technique for leprosy is required, especially, for children to assist diagnosis of single lesion pauci bacillary (SLPB) cases that are considered early lesions as many children with suspicious SLPB cases do not off and on comply properly during examination in eliciting responses as I had seen at our OPD. Other important problems encountered, now and then, at our OPD and need attention are recurrent ENL in some Borderline Lepromatous (BL), subpolar Lepromatous (LLs) and Lepromatous Leprosy (LL) patients (presumably $30 \%$ in our OPD in my view), though majority of the above types of MB cases have been found escaped this morbid and dangerous complication in our clinic. Fragmented bacilli, the causative factor of ENL, are cleaned up gradually by the reticuloendothelial cells of the host. But how faster bacterial clearance can be achieved to prevent further ENL and the associated complications is the subject of discussion today. Silent neuritis occurring suddenly without any prior warning, especially, during surveillance period as I had seen, needs further studies to help the clinician. So, is the case for residual skin lesions that sometimes persist even after therapy and these quite often pose difficulty in acceptance of the patients in the society and compel victims to move from one physician to another in search of cure. Last, but not the least, cessation of therapy (MDT) after one year in some MB cases, especially with high BI (4+ and higher) when ATP activities are remaining high ${ }^{9)}$ may invite a serious problem in future in the form of a relapse/secondary MDR leprosy as therapy is inadequate in my views in these cases.

\section{Acknowledgment}

I deeply and thankfully acknowledge to Dr. $\mathrm{H}$. Nomaguchi, Chief of Lab.-1, Leprosy Research Center, National Institute of Infectious Diseases and Dr. B. K. Das, Joint Director (Microbiology), RLTRI, Gouripur, Bankura, WB, India for providing me NLEP India report 1998-99.I am specially grateful and feel obliged to Ministry of Health \& Family Welfare, Govt. of India, New Delhi and to my department, RLTRI, Gouripur, Bankura for selection to pursue JICA course.

\section{References}

1) Weekly Epidemiological Record, No 28, 14th July (2000).

2) Jopling $W \mathrm{H}$, Hand Book of Leprosy, third edition, p 4-5 (1984).

3) Perk \& Perk, Preventive \& Social Medicine, 12th edition, Leprosy p. 210-221.

4) Annual Report 1984-85, Government of India, Ministry of Health \& Family Welfare, 1985.

5) Govt. of India, Ministry of H\&FW, New Delhi, Report of the Working Group on the Eradication of Leprosy (1982).

6) Rao, C.K et. al. Indian Journal of Leprosy 59 (2) 203 (1987).

7) NLEP India, Progress report for case detection, treatment \& discharge, Govt.of India, Ministry of Health \& Family Welfare (1998-99).

8) Leprosy Review, second round MLEC, in Orrisa, India 71 (2) 240 (2000).

9) Katoch K et. al. Int.J.Lepr. Other Myco.Dis 59(2) 248-54 (1991). 